\title{
Review of Risk Assessment and Mitigation Measures of Coastal Aquifers Vulnerable to Saline Water Intrusion
}

\author{
Sudip Basack ${ }^{1 *}$, M K Loganathan², Ghritartha Goswami \\ Parinita Baruah ${ }^{4}$, Rashidul Alam ${ }^{5}$ \\ ${ }^{1}$ Elitte College of Engineering, Affiliation: MAKA University of Technology, Kolkata, India \\ ${ }^{2}$ School of Engineering and Technology, The Assam Kaziranga University, Jorhat, Assam, India \\ ${ }^{3}$ Department of Civil Engineering, North Eastern Regional Institute of Science and Technology, \\ Nirjuli, Arunachal Pradesh, India \\ ${ }^{4}$ North Eastern Hydraulic and Allied Research Institute, Rudreswar, Assam, India \\ ${ }^{5}$ Department of Civil Engineering, North Eastern Regional Institute of Science and Technology, \\ Nirjuli, Arunachal Pradesh, India
}

Received: 8 June 2021

Accepted: 18 September 2021

\begin{abstract}
The extent of risk is the key measure of sustainable performance of engineering and natural systems and coastal aquifers are no exceptions. Aquifers in the coastal regions are vulnerable to saltwater intrusion (SWI) that attributes to the degradation of freshwater quality in the aquifers. The major factors that influence saline water intrusion are sea level rise due to climate change and the impact of human activities. The water quality erodes rapidly when these factors act simultaneously. Abstraction Desalinization Recharge (ADR) and Qanat-well structure methods are found to be effective methods to mitigate the risk in terms of cost and abstraction of groundwater in specific regions without intensifying saltwater intrusion. Risk management studies are useful to assess the vulnarabilty and economic loss involved in coastal aquifer management. In this paper, a review of risk assessment and mitigation measures of coastal aquifers vulnerable to saltwater intrusion is presented.
\end{abstract}

Keywords: coastal aquifer, risk management, saltwater intrusion

\section{Introduction}

Risk assessment and mitigation measures are the key activities that help to identify hazards and risk factors that have a potential impact on any system,

e-mail: basackdrs@hotmail.com such as an engineering system or a natural system [1]. There have been several emerging studies on risk assessment of various systems ranging from natural systems to manufacturing systems [2-9]. It is observed from the literature that the risk studies have helped to improve the resilience of natural systems to some extent [10]. Although some attempts made to tackle the vulnarabilty issues of coastal aquifers, yet their risk 
analyses and mitigation measures are not fully explored in terms of qualitative and quantitative indices due to the unpredictable quality degradation of the aquifers resulted from intrusion of saline water. This work, however, attempts to analyse if the existing literature suffice to address the risk-related issues of coastal aquifers that are affected by SWI, and provide critical analysis for future research direction in risk assessment of coastal aquifers vulnerable to SWI.

The natural systems like coastal aquifers are vulnerable to several man- made activities and natural phenomena [11]. The influence of salt water prominently by the coastal areas in the ground aquifers have significantly depleted the amount of fresh ground water that we pump out for our regular activities including drinking due to which desalinization is prerequisite. This is a primary concern where particularly in coastal areas the salinity of sea water causes the migration of salt water to the fresh ground water interface making it gradually unusable and determining the boundary layer between saltwater and groundwater becomes tedious due to linkage of hydraulic gradients between aquifers and sea. The excessive withdrawals that decreases the ground water levels and the upward movement of deep saline zones towards the aquifer gradients influences the saltwater intrusion naturally or anthropogenically. This saltwater intrusion also affects the agriculture and production of crops. However, analyzing the physiochemical parameters of water from open wells or bore wells or pumps can be used for predicting the intrusion of saltwater and a restoration model can be framed out based on the analysis.

Climatic occurrences such as Tsunami have a tremendous contribution in contaminating coastal aquifers through direct infiltration in form of flood waves and pond formation inflicting large scale damage and scarcity of water for drinking and other regular purposes. Also, lower hydraulic head of an aquifer is more susceptible to saltwater intrusion if the later has high hydraulic head or else the freshwater can flow into the sea if has high gradient than the sea. Also, rise in sea levels due to climate change and global warming with the thermal expansion of sea and decrease in river discharge due to construction of dams in river upstream which is also responsible for change in river course and discharge capacity along with poor infiltration rate of grounds for refilling of groundwater and rapid urbanization which has reduced the area of infiltration by spreading its concrete surface over the ground are some of the factors that assist in intrusion of saltwater in freshwater.

The authors propose a framework of saline water intrusion risk assessment that shown in Fig. 1, while the fishbone diagram, which is extensively used in risk assessments of engineering system, has been employed to depict in case of saline water intrusion in Fig. 2.

This study will help at managing the intrusion of saltwater at the ground aquifer through risk analysis in tandem that would encourage the mitigation and conservation of freshwater along the coastal areas of India.

\section{Methodology}

Theoretical analysis has been done for investigating the current situation of saltwater intrusion from sea to freshwater aquifers along with pictorial representation of the sea-ground interface for highlighting the basic causes of saltwater intrusion in ecological fluxes and its risk factors relating to demand for drinking water, decline in agriculture outputs and population. The basic phenomena of saline water intrusion with associated coastal groundwater management are shown in Fig. 3 and 4 [12, 13].

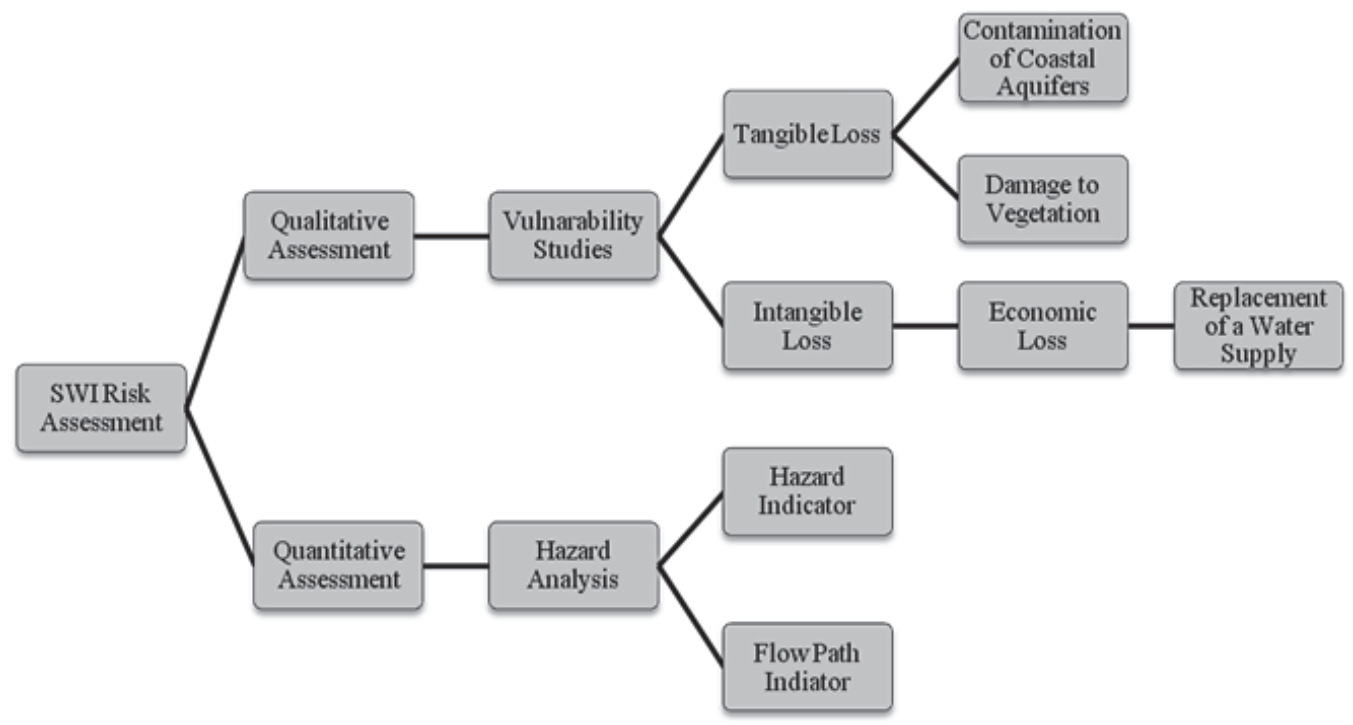

Fig. 1. Framework of saline water intrusion risk assessment. 


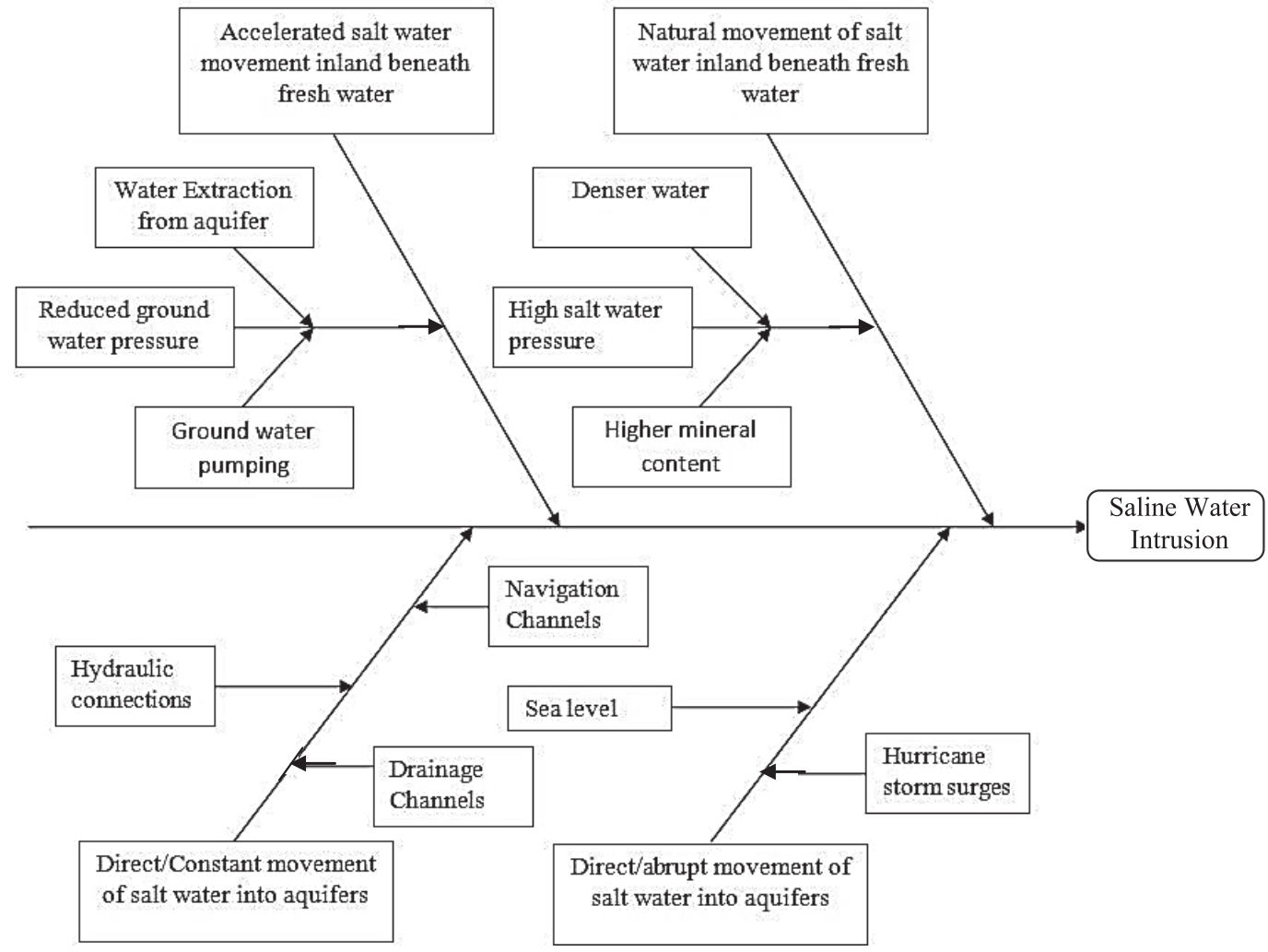

Fig. 2. Fish-bone diagram of saline water intrusion.

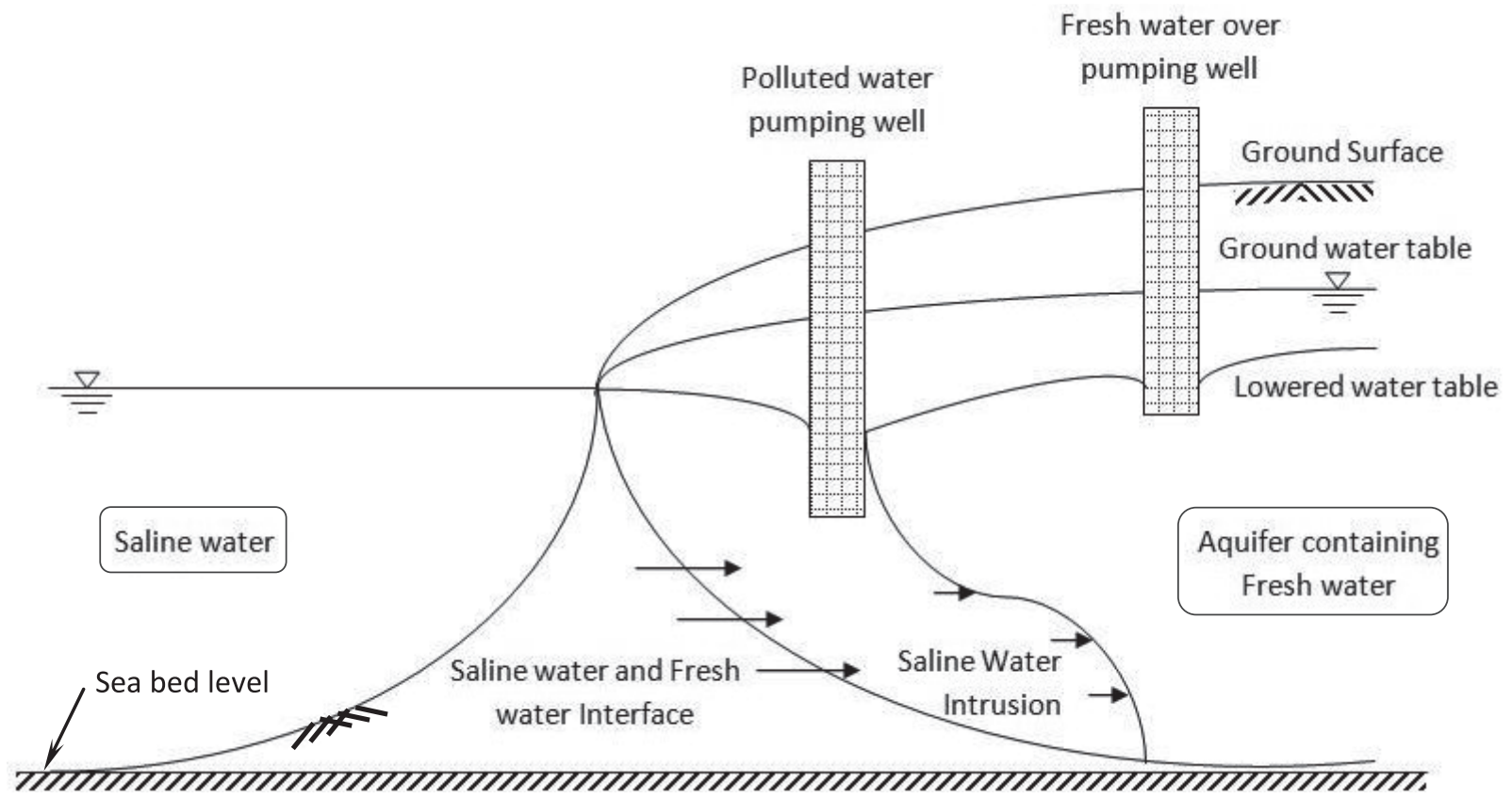

Fig. 3. Saline water freshwater interface.

\section{Review of Literature}

The research findings obtained by different researchers in the field of study have been briefly described in this section. The sequence followed herein is chronological, i.e., ascending year-wise. Apart from describing the work done, the advantages and shortcomings of each of the past contributions have been included as well.

Das and Datta [14] proposed a nonlinear optimization technique using steady state and transient analyses to solve the saltwater intrusion problem. The 


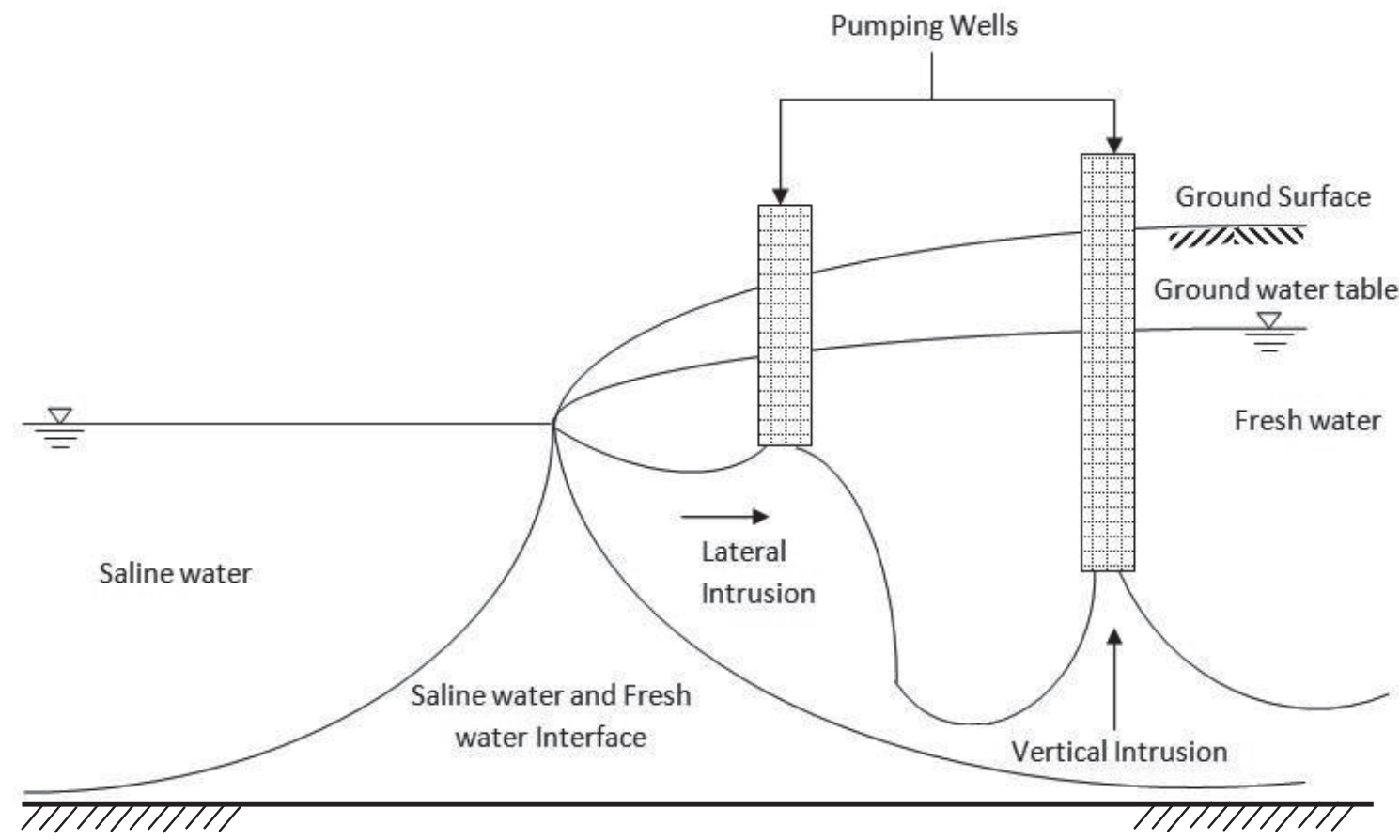

Fig. 4. Lateral and vertical saline water intrusion.

method was utilized to obtain total sustainable yield from coastal aquifers under the constraint of saltwater intrusion. The advantage of the model was its simplicity and applicable to coastal groundwater management, while other study aspects like submarine groundwater discharge have not been covered.

Canales et al. [15] conducted a field investigation in Boca Abierta Valley, Mexico to estimate the risk of saline water intrusion by considering ground water quality, hydro-stratigraphic conditions and balance equations terms. From the investigation they have assigned risk weighting factor for each of the above elements such as high risk for the lack of geological boundaries, medium risk for the groundwater quality and medium-high risk for the balance equation terms. Overall, they anticipated medium to high risk of getting a severe salty water intrusion in the groundwater pumping area of the study area. While the work is of practical interest so far as the risk categorization is concerned, several other important factors including high pumping rates, natural and artificial recharge are not covered.

Wellington Regional Council [16] conducted theoretical investigation on risk management models for artesian aquifer. The investigation was based on long term ground water monitoring record, previous research studies and analysis of the system performance using Hutt Aquifer Model. Their study recommended improvements in the existing monitoring systems as well as construction of another monitoring site in the vicinity of the old monitoring bore. Various important study aspects like the hydrogeological setting, sub-harbour aquifer characterization, saltwater intrusion potential, etc. were well covered, although recommendations on risk management of saline water intrusion requires more investigation.

Lecca and Cau [17] generated a stochastic simulation model to perform risk-based investigation in coastal aquifers of Oristano, Italy. The outcome evidently forecasted that appropriate consideration of aquitard heterogeneities is enormously vital to assess the possible risk of ground water contamination and reconstruction of groundwater flow patterns along with contamination mechanisms and the mixing between upper and lower groundwater levels. The authors suggested further investigation on cost effectivity for mitigation techniques for environmental protection.

Ball and Campbell [18] developed a GIS based tactic for evaluation of saline water intrusion risk to aquifers generated by construction of the abstraction borehole nearby the coast. The GIS maps are helpful in identification of boreholes which can be excluded from investigation, minimizing the investigation time for hydrologist. The work is quite interesting, covering the important aspects of saline water intrusion including aquifer characteristics, hydraulic gradient, rate of abstraction and shoreline distance, although the appropriate mitigation measures were not highlighted.

Loáiciga et al. [19] carried out risk assessment study to simulate saline water intrusion using finite element method by variable density method. The study revealed that rise in sea level increases the risk of saline water intrusion. Although limited to the local area concerned, this interesting field-based contribution is beneficial to hydrogeological researchers.

Basack et al. [20] carried out laboratory-based model tests with associated analytical studies to investigate the saltwater intrusion and submarine groundwater recharge 
in granular soil and found that both the processes are time dependent and functions of saltwater densities and model dimensions. Although the experimental observations and analytical results are interesting, its specific application in the field from the viewpoint of hydrogeological heterogeneity has not been discussed in the paper.

Taclan [21] conducted his study in aquifers of Ilocos Norte to identify the potential risk factors associated with saline water intrusion and to provide precautionary measures. As high chloride content was found in the study area the authors recommended using freshwater recharge as a preventive measure.

Altalmas [22] have conducted his study using FEM-MODFLOW, a three-dimensional numerical simulation model coupled with finite element modeling to understand how saline water intrusion increased the chloride concentration along with reduce in groundwater level in North of Gaza Strip. The author observed that artificial recharge is not an effective technique to mitigate the saltwater intrusion problem due to high abstraction rate and hence, recommended further investigations to find a suitable method to reduce such abstraction.

Werner et al. [23] carried out a thorough review on saltwater intrusion problem and observed that saline water intrusion is a global issue aggravated by escalation rates of demands of freshwater in coastal zones. The author identified the seawater intrusion as an active research field with substantial unresolved issues including spatial heterogeneity, environmental uncertainty, etc., but adequate review on remedial measures were not carried out.

Mazi [24] conducted analytical studies to quantify the risk of saline water intrusion under absolute conditions. The results show that the hydro-climatic conditions and fluctuation in ground water pumping along with sea level rise can become major cause of heavy saline water intrusion in coastal aquifer. The author observed that groundwater recharge is the most effective solution to mitigate the saltwater intrusion problem, but under declining recharge, the pumping of coastal water is not sustainable.

Basack et al. [25] developed a practical coastal groundwater management model with Indian case study using Qanat-Well structure with associated recharge techniques. The model developed was validated with a case study in a coastal locality in the east coast of India. They informed that the model is specifically applicable to limited and not-so urbanized coastal regions, thereby limiting its universal applicability.

Arumugam and Saraswathi [26] conducted a risk evaluation investigation on saline water intrusion in Adirampattinam, India. They found that several ground water samples collected from study area was having greater salinity than allowable limits and it is due to saline water intrusion occurring from very long time. However, a detailed investigation on spatial variation of saltwater intrusion in the study area was not done.
They also framed a model restoration strategy to reduce saline water intrusion in the particular area but did not provide a detailed quantification on its effectivity.

Klassen and Allen [27] have investigated the coastal aquifers of Gulf Islands in British Columbia to conduct test on newly developed risk assessment approach of saline water intrusion caused by over-pumping and various natural hazard such as sea level rise, climate change and storm surge. To estimate the storm surge data, they have collected past data of all the hazards causing saline water intrusion and integrated them with projected sea level rise. The result is combined with maps presenting density of pumping wells and coastal zones with higher risk of saline water intrusion. The risk was assessed spatially using an economic valuation of loss. This is a creditable field-based study pertaining to risk analysis of seawater intrusion in the study area, although no investigation was done on adopting proper mitigation measures.

Klassen et al. [28] identified several hazard responsible for saline water intrusion and mapped the datasets separately for comparison of results. The results obtained by combining chemical composition and risk assessment maps are useful for decision making and monitoring coastal water management.

Kayode et al. [29] briefly reviewed and discussed about the possible reasons for saline water intrusion and different methods for management of saline water intrusion. They found that ADR (Abstraction, Desalination and Recharge) as the most cost-effective method to control saline water intrusion into coastal region. Although the authors presented a brief overview on the causes and factors of saline water intrusion into coastal regions and possible remedial measures, adequate quantifications supported by data could make the study more interesting.

Elsayed et al. [30] found that the process of storminduced vertical saline water intrusion was significantly detrimental, as observed via an integrated modeling approach of the processes utilizing a numerical software. The study suggested that risk of storminduced saline water intrusion could be minimized by sub-surface drainage networks which was found to be more efficient in comparison with other mitigation methods. A further investigation on the relative benefits of various mitigation measures would be more interesting.

Eriksson et al. [31] conducted field-based study using GIS software to estimate fundamental conditions associated with the risk of saline water intrusion on the Baltic Sea island of Öland, Sweden. They found out the impact of geomorphological and geophysical parameters on the risk of saline water intrusion and to develop a salinization risk map. The authors appreciably studied diversified aspects relevant to the saltwater intrusion and the associated risk management including distance from shoreline, sea level rise, well density and inundation, precipitation, soil type, etc., adequate mitigation measures were not studied. 
Table 1. Summarized contributions on risk assessment and mitigation measures relevant to saline water intrusion.

\begin{tabular}{|c|c|c|}
\hline Publications & Risk Assessment & Mitigation Measures \\
\hline Goswami et al. [12] & Critical review of existing contributions & Critical review of existing contributions \\
\hline Basack et al. [13] & Laboratory model tests & Artificial recharge \\
\hline Das and Datta [14] & $\begin{array}{c}\text { Nonlinear optimization technique to obtain total } \\
\text { sustainable yield }\end{array}$ & $\begin{array}{l}\text { Applicability of proposed solutions to coastal } \\
\text { groundwater management }\end{array}$ \\
\hline Canales et al. [15] & Field based investigation to categorize risk levels & No specific mitigation measures were studied \\
\hline $\begin{array}{l}\text { Wellington Regional } \\
\text { Council [16] }\end{array}$ & $\begin{array}{l}\text { Analysis of groundwater monitoring record and system } \\
\text { response }\end{array}$ & $\begin{array}{l}\text { Limited recommendation on remedial measures to } \\
\text { mitigate saltwater intrusion }\end{array}$ \\
\hline Lecca and Cau [17] & $\begin{array}{l}\text { Stochastic simulation model for risk analysis in coastal } \\
\text { aquifers }\end{array}$ & $\begin{array}{l}\text { Authors suggested further investigation on cost } \\
\text { effectivity of mitigation techniques }\end{array}$ \\
\hline $\begin{array}{l}\text { Ball and Campbell } \\
\qquad[18]\end{array}$ & $\begin{array}{c}\text { GIS based methodology for risk assessment of } \\
\text { saltwater intrusion }\end{array}$ & $\begin{array}{c}\text { Appropriate mitigation measures were not } \\
\text { highlighted }\end{array}$ \\
\hline Loáiciga et al. [19] & $\begin{array}{l}\text { Finite element method by variable density method to } \\
\text { study localized saltwater intrusion }\end{array}$ & No specific mitigation measures were studied \\
\hline Basack et al. [20] & $\begin{array}{l}\text { Laboratory model study followed by analytical work } \\
\text { on the flow of saltwater through porous medium }\end{array}$ & No specific mitigation measures were studied \\
\hline Taclan [21] & $\begin{array}{l}\text { Field-based investigation to assess potential risk } \\
\text { factors on saline water intrusion }\end{array}$ & $\begin{array}{c}\text { Artificial recharge was identified as a mitigation } \\
\text { technique }\end{array}$ \\
\hline Altalmas [22] & $\begin{array}{l}\text { FEM-MODFLOW coupled analysis on saltwater } \\
\text { intrusion for evaluating risk }\end{array}$ & $\begin{array}{l}\text { Suggested further study to assess proper mitigation } \\
\text { technique }\end{array}$ \\
\hline Werner et al. [23] & Intensive review works up to 2013 & Review on mitigation measures was not included \\
\hline Mazi [24] & $\begin{array}{l}\text { Analytical studies to quantify the risk of saline water } \\
\text { intrusion }\end{array}$ & $\begin{array}{l}\text { Groundwater recharge together with controlled } \\
\text { coastal pumping }\end{array}$ \\
\hline Basack et al. [25] & $\begin{array}{l}\text { Coastal groundwater management model with Indian } \\
\text { case study }\end{array}$ & $\begin{array}{l}\text { Artificial rainwater harvesting with recharge wells } \\
\text { and ponds }\end{array}$ \\
\hline $\begin{array}{l}\text { Arumugam and } \\
\text { Saraswathi [26] }\end{array}$ & $\begin{array}{l}\text { Risk evaluation investigation on saline water intrusion } \\
\text { in south India }\end{array}$ & $\begin{array}{l}\text { Framed a model restoration strategy, but no detailed } \\
\text { study }\end{array}$ \\
\hline $\begin{array}{l}\text { Klassen and Allen } \\
{[27]}\end{array}$ & $\begin{array}{l}\text { Field-based study in British Columbia to develop risk } \\
\text { assessment approach on saltwater intrusion }\end{array}$ & $\begin{array}{c}\text { No investigation was carried out on mitigation } \\
\text { measures }\end{array}$ \\
\hline Klassen et al. [28] & $\begin{array}{l}\text { Risk assessment mapping in saline affected coastal } \\
\text { zones }\end{array}$ & Monitoring of coastal water management \\
\hline Kayode et al. [29] & $\begin{array}{l}\text { Reviewed possible reasons for saline water intrusion } \\
\text { and different methods for its management }\end{array}$ & $\begin{array}{l}\text { ADR was found to be most effective mitigation } \\
\text { technique }\end{array}$ \\
\hline Elsayed et al. [30] & $\begin{array}{l}\text { Integrated modeling by numerical software to study } \\
\text { storm induced vertical saline water intrusion }\end{array}$ & Development of sub-surface drainage networks \\
\hline Eriksson et al. [31] & $\begin{array}{l}\text { Estimating risk of saline water intrusion on Baltic Sea } \\
\text { island by GIS software }\end{array}$ & Mitigation measures were not studied \\
\hline Maity et al. [32] & $\begin{array}{l}\text { Field-based study on saltwater intrusion in coastal } \\
\text { West Bengal }\end{array}$ & $\begin{array}{l}\text { Presented plans for rural and urban areas like } \\
\text { rainwater harvesting and aquifer restoration }\end{array}$ \\
\hline Morgan [33] & $\begin{array}{c}\text { Groundwater flow modelling at Wellington Harbour to } \\
\text { evaluate the risk of saline water intrusion }\end{array}$ & $\begin{array}{l}\text { Limited information is available on mitigation and } \\
\text { control techniques }\end{array}$ \\
\hline $\begin{array}{l}\text { Senthilkumar et al. } \\
\qquad[34]\end{array}$ & $\begin{array}{c}\text { Geochemical and geophysical techniques using GIS } \\
\text { software to study groundwater quality and saltwater } \\
\text { intrusion in Tamil Nadu. }\end{array}$ & No specific information on control and mitigation \\
\hline Shammi et al. [35] & $\begin{array}{c}\text { Study on health hazards by consumption of salinity } \\
\text { affected groundwater }\end{array}$ & No specific information on control and mitigation \\
\hline
\end{tabular}

Maity et al. [32] conducted field-based study on a coastal district namely Purba Midnapur, West Bengal in India. The area was under high risk of deterioration of fresh groundwater by saline water intrusion. They presented set of plans for rural and urban areas including rainwater harvesting and aquifer improvement for restoration of the aquifer to reduce the risk saline water intrusion and improve the quality of groundwater. The merits and demerits of the proposed plans including the cost efficiency was presented 
in the paper. A more intrinsic study from the viewpoint of fluid mechanics and hydrogeology has not been done by the authors.

Morgan [33] incorporated ground water flow model of Wellington Harbour exploration bores project to evaluate the risk of saline water intrusion. The reviewed model was based on Hutt Aquifer Model with variable density flow and transport. The results identified backflow of seawater, vertical leakage through harbour floor and seepages as the major factors generating risk of saline water intrusion. The work includes evidence of important research findings, although limited information is available on mitigation and control techniques.

Senthil Kumar et al. [34] conducted integrated geochemical and geophysical techniques to study the quality of groundwater and saline water intrusion in Thiruvallur district, Tamil Nadu. They used GIS software to define the location of freshwater zones and the regions undergoing saline water intrusion. The groundwater sample collection and analysis were done through piper diagram and Chada's plot. The geoelectrical resistivity survey was conducted as well. The contribution appears to be creditable so far as the quantification of saltwater intrusion in the study area, more information on the associated risk analysis and mitigation would be better.

Shammi et al. [35] emphasized on driver pressure state impact response framework for drinking water sodium along with studies on salinity intrusion and their impacts on human health. The study primarily focused on risk to human health generated by increased sodium content in drinking water. The study area was focused on coastal Bangladesh. Although the study is useful from the viewpoint of adverse health hazards initiated by consumption of salinity affected groundwater, and few studies are also conducted on pre-monsoon and post-monsoon spatial salinity distribution in the study area, the work is of limited applicability to the relevant risk analysis and mitigation measures.

\section{Critical Analysis}

The summarized contributions have been shown in Table 1. Brief analysis of the saltwater intrusion in freshwater discloses the potential hazards it imparts to human and agriculture outputs highlighting its root causes as over-pumping of the groundwater and poor or lesser potential of ground to infiltrate the natural precipitation. Also, it has been identified that rise in sea water due to global warming and excessive presence of greenhouse gases have led to flow of sea water into ground aquifers through the hydraulic gradients or waves. Although numerical assessment has been carried out for addressing the situation of contamination of fresh ground water by saline water from the sea by the researchers, yet the potential remedy for preventing saline water intrusion or preserving the aquifers from being inflicted by sea water is still in prelude stage. From the literature survey it is observed that qualitative and quantitative models of risk assessment were also not implemented effectively. Since risk assessment study helps to assess the vulnarabilty and economic loss, it has broad scope in investigations relevant to saline water intrusion.

\section{Conclusions}

Sea water due to its high salinity is inappropriate for human consumption, irrigation purposes, construction uses and others as it is detrimental for several other activities as well. The global limitation of potable water for drinking is at risk primarily for countries possessing sea boundaries. So, there is a global need for a process that would help in overcoming the risk of sea water intrusion in the freshwaters. The paper has presented a review of available literature pertaining to the risk management and mitigation measures of coastal aquifers vulnerable to saline water intrusion and provides guidance to identify the research gaps in this direction.

\section{Acknowledgments}

The infrastructural supports received from Pinnacle Educational Trust, Kolkata, India and North Eastern Knowledge Foundation are acknowledged. The authors also thank the anonymous reviewer for painstaking effort in reviewing the article.

\section{Conflict of Interest}

The authors declare no conflict of interest.

\section{References}

1. KUNREUTHER, H. Causes of Under insurance against Natural Disasters. The Geneva Papers on Risk and Insurance, 9 (31), 206, 1984.

2. McALEER M. Prevention Is Better Than the Cure: Risk Management of COVID-19. Journal of Risk and Financial Management, 13 (3), 46, 2020.

3. SARAH D., CLAUDIA R.S., JOHN K., ALEXANDRA L.J.F., GABRIEL R., ANNE MARTHE V.B., DAVID S., SANDER V.L. Risk perceptions of COVID-19 around the world, Journal of Risk Research, 23 (7-8), 994, 2020.

4. FANG C., DONG P., FANG Y-P, ZIO E. Vulnarabilty analysis of critical infrastructure under disruptions: An application to China Railway High-speed. Proceedings of the Institution of Mechanical Engineers, Part O: Journal of Risk and Reliability. 234 (2), 235, 2020.

5. ZIO E. Challenges in the vulnarabilty and risk analysis of critical infrastructures, Reliability Engineering \& System Safety, 152, 137, 2016. 
6. LOGANATHAN M.K., NEOG S.S., RAI S. Process Safety and Performance Improvement in Oil Refineries Through Active Redundancy and Risk Assessment Method - A Case Study. 2018 IEEE International Conference on Industrial Engineering and Engineering Management (IEEM), 98, 2018

7. LOGANATHAN M.K., BEZBAURAH I, GANDHI O.P., BORAH R.C. Criticality analysis of wind turbine energy system using fuzzy digraph models and matrix method. In: Haugen S et al (eds) Safety and reliability - safe societies in a changing world. Taylor \& Francis Group, London, 1727, 2018. ISBN 978-0-8153-8682-7.

8. LOGANATHAN M.K. Reliability and availability studies of automotive manufacturing systems with consideration of structure and maintenance cost, Ph. D. Thesis submitted at IIT Delhi. 2015. [http://eprint.iitd.ac.in/bitstream/ handle/2074/8187/TH-4879.pdf?sequence=1]

9. AVEN T., FLAGE R. Foundational challenges for advancing for the field and discipline of risk analysis. Risk Analysis. 40, 2128, 2020.

10. KUNREUTHER H. Risk management solutions for climate change-induced disasters. 2020. https:// onlinelibrary.wiley.com/doi/10.1111/risa.13616.

11. FERGUSON G. GLEESON T. Vulnarabilty of coastal aquifers to groundwater use and climate change. Nature Climate Change, 2, 342, 2012.

12. GOSWAMI G., BASACK S., MASTORAKIS N., SAIKIA A., NILO B., AHMED N. Coastal groundwater flow and management: a state-of-the-art review. International Journal of Mechanics, 14, 37, 2020. http://doi. org/10.46300/9104.2020.14.5.

13. BASACK S., GOSWAMI G. SONOWAL S. A Laboratory Study on the Influence of Saltwater Intrusion on Sand relevant to Coastal Environment. Technical Presentation, Indian Science Congress, Bengaluru, India, Engineering Science Section: 65, 2020.

14. DAS A., DATTA B. Optimization based solution of density dependent seawater intrusion in coastal aquifers. Journal of Hydrological Engineering, 5, 82, 2000.

15. CANALES A., GONZALEZ R., ISLAS L. Salt water intrusion risk assessment in the Boca Abierta Valley, Sonora, Mexico. First International Conference on Saltwater Intrusion and Coastal Aquifers - Monitoring, Modeling, and Management. Essaouira, April 23-25, Morocco. 2001.

16. WELLINGTON

REGIONAL

COUNCIL INVESTIGATIONS DEPARTMENT TECHNILCAL REPORT. RINV-T-01/26. 2001.

17. LECCA G., CAU P. Stochastic modeling for seawater intrusion risk assessment in exploited coastal aquifers: the Oristano case study, Italy. Hydrology and Water Resource Management, 1, 2002.

18. BALL D., F. CAMPBELL E. Saline intrusion: a screening tool for the assessment of risk to coastal aquifers in Scotland. British Geological Survey, CR/06/025N, 1, 2006.

19. LOAICIGA H.A., PINGEL T.H., GARCIA E.S. Assessment of saline water intrusion potential from sealevel rise in coastal aquifer of California. University of California Water Resource Center Technical Completion Report, 2009, 1, 2009.

20. BASACK S., BHATTACHARYA A.K., SAHANA C., MAITY P. A study on saline water intrusion and freshwater recharge relevant to coastal environment. WSEAS Transactions on Fluid Mechanics, 5 (3), 80, 2010.

21. TACLAN L.B., Risk assessment of saline water intrusion. National Academy of Science and Technology, 33 (1), 2011.

22. ALTALMAS M. Risk assessment and mitigation of the seawater intrusion using Modeling Approach. The Islamic University of Gaza, Master Thesis. 1, 2012.

23. WERNER A.D., BAKKER M., POST V.E.A., VANDENBOHEDE A., LU C., ASHTIANI B.A., SIMMONS C.T., BARRY D.A. Seawater intrusion processes, investigation and management: recent advances and future challenges. Advances in Water Resource, 51, 3, 2013.

24. MAZI A., Seawater intrusion risks and controls for safe use of coastal groundwater under multiple change pressures. US-AB, Volume 4, 1, 2014.

25. BASACK S., BHATTACHARYA A.K. MAITY P. A coastal groundwater management model with Indian case study. Water Management, 167 (3), 126, 2014. https:// doi.org/10.1680/wama.12.00008

26. ARUMUGAM K., SARASWATHI S. Risk assessment study of sea water intrusion and probable remedial measures: groundwater quality at Adirampattinam, East coast of Tamil Nadu, India. International Conference on Pollution and Sustainable Environment, April 25-26, Dubai, 2016.

27. KLASSEN J. ALLEN D.M. Risk of saltwater intrusion in coastal bedrock aquifers: Gulf Islands, BC. Department of earth science, Project Report, 1, 2016.

28. KLASSEN J., ALLEN D.M. Assessing the risk of saltwater intrusion in coastal aquifers. Journal of Hydrology, 551, 730, 2017

29. KAYODE O.T., ODUKOYA A.M., ADAGUNODO T.A. Saline water intrusion: its management and control. Journal of Informatics and Mathematical Sciences, 9 (2), 493, 2017

30. ELSAYED S.M., OUMERACI H. Modelling and Management of Storm-driven saltwater intrusion in freshwater aquifers: the case of near Bremerhaven, Germany. Integrating Ecosystem in Coastal Engineering aquifers, Volume 19, 1, 2017.

31. ERIKSSON M., EBER, K., JARSJO J. Well salinization risk and effects of Baltic sea level rise on the groundwaterdependent island of Oland, Sweden. Water, 141 (10), 1, 2018.

32. MAITY P.K., DAS S., DAS R. Remedial measures for saline water ingression in coastal aquifers of south West Bengal in India. MOJ eco environ science, 6 (1), 17, 2018.

33. MORGAN L. Peer review of saline intrusion model risk assessment for the exploration phase of the Wellington harbour exploitation bores project. Wellington Water Limited, 1, 2018.

34. SENTHILKUMAR S., VINODH K., BABU G.J., GOWTHAM B., ARULPRAKASAM V. Integrated seawater intrusion study of coastal region of Thiruvallur district, Tamil Nadu, South India. Applied Water Science, 124 (9), 2, 2019.

35. SHAMMI M., RAHMAN M.M. BONDAD S.E., DOZA M.B. Impacts of salinity intrusion in community health: a review of experiences on drinking water sodium from coastal areas of Bangladesh. Healthcare, $\mathbf{5 0}$ (7), 1, 2019. 